\title{
Significados e sentidos atribuídos ao Centro de Atenção Psicossocial Álcool e outras Drogas (CAPS AD) por seus usuários: um estudo de caso
}

Clarissa de Barros Lacerda ${ }^{(a)}$

Marta Fuentes-Rojas ${ }^{(b)}$

Lacerda CB, Fuentes-Rojas M. Meanings attributed to Psychosocial Care Center - Alcohol and Other Drugs (CAPS AD) by its users: a case study. Interface (Botucatu). 2017;

21(61):363-72.

This paper aims to present the meanings that a Psychosocial Care Center - Alcohol and Other Drugs (CAPS AD) has from the point of view of its users. This qualitative study made semi-structured interviews with 11 patients currently followed by the CAPS AD. The most present meanings and senses in the discourse indicated a positive relationship with the service, seen as a place of support and care. It was also found that the CAPS, considered as a welcoming place that provides access to rights beyond health, must decide between access to rights and the construction of autonomy, so that the service does not stop acting in the social sphere and it can also promote social integration and empowerment of these individuals.

Keywords: CAPS AD. Meanings. Drugs.
Este artigo tem por objetivo apresentar os significados e sentidos de um Centro de Atenção Psicossocial Álcool e outras Drogas (CAPS AD) para seus usuários. Neste estudo de caráter qualitativo, foram realizadas entrevistas semiestruturadas com 11 usuários em acompanhamento no serviço. Os significados e sentidos mais presentes nos discursos indicaram uma relação positiva com o serviço, visto como um local de apoio e cuidado. Constatouse, também, que o CAPS, ao se mostrar como um local acolhedor e que proporciona o acesso a direitos para além da saúde, precisa ponderar entre o acesso a direitos e benefícios e a construção de autonomia, de forma que o serviço não deixe de atuar no âmbito social, mas, também, possa promover a reinserção social e o empoderamento desses indivíduos.

Palavras-chave: CAPS AD. Significados e sentidos. Drogas.

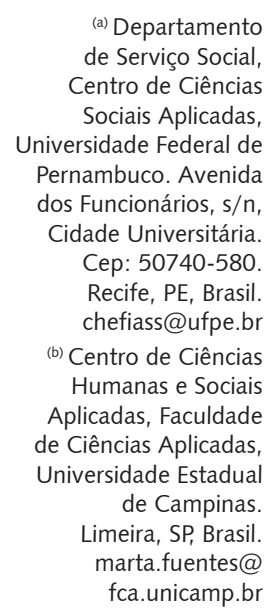

(a) Departamento de Serviço Social, Centro de Ciências Sociais Aplicadas, Universidade Federal de Pernambuco. Avenida dos Funcionários, s/n, Cidade Universitária. Cep: 50740-580. Recife, PE, Brasil. chefiass@ufpe.br (b) Centro de Ciências Humanas e Sociais Aplicadas, Faculdade de Ciências Aplicadas, Universidade Estadual de Campinas. Limeira, SP, Brasil. marta.fuentes@ fca.unicamp.br 


\section{Introdução}

A prática humana de consumir substâncias que proporcionam "alterações na percepção, no humor e no sentimento"1 (p. 13) acontece há milhares de anos, caracterizando-se como um ato ancestral. Permeado por razões diversas, o consumo de tais substâncias - comumente denominadas de drogas envolve fatores culturais, religiosos, econômicos e políticos, entre outros.

É factível que, mesmo fazendo parte de rituais de sociabilidade, transcendência e autoconhecimento, o consumo de drogas, se descomedido, somado a outros fatores relacionados à vida dos usuários, pode gerar uma dependência. Para além dos contextos ritualísticos e de toda a historicidade dessa prática na humanidade, o uso de substâncias com efeitos psicoativos pode, muitas vezes, ser feito de maneira desenfreada. Nesse sentido, é possível que um uso prazeroso perca seu potencial de proporcionar satisfação e se transfigure numa dependência física e psicológica do indivíduo com a substância ${ }^{2-4}$.

$\mathrm{Na}$ contemporaneidade, usar drogas de forma abusiva é visto como um problema social e de saúde ${ }^{5}$. Vários foram os termos criados para denominar os indivíduos que consomem essas substâncias de maneira exagerada, e, entre tantos conceitos, o mais aceito atualmente é o de "dependência" 3,6 .

A transição entre os séculos XIX e XX marcou o período em que esse fenômeno ancestral passou a ser assimilado como um problema social. Como discorrem Labate et al. ${ }^{5}$, "tal qual a violência, a miséria e as doenças, o uso de 'drogas' foi alocado no panteão dos males que afligiram a humanidade no século passado" (p. 23). Como resposta ao problema, o Estado vem se incumbindo de controlar e reprimir a produção e uso de substâncias consideradas ilícitas, ações estas respaldadas por tratados internacionais ${ }^{7}$. Esse modelo de abordagem é denominado, por vários autores, como proibicionista, uma vez que se utiliza da proibição como estratégia primordial para redução da oferta, do consumo e do consequente abuso de drogas ilícitas ${ }^{8}$.

No momento em que o consumo abusivo de drogas passou a ser visto como um problema, houve o surgimento de medidas para enfrentamento dessa nova questão, ora pautadas na criminalização do uso e proibição de determinadas substâncias, ora guiadas pelo viés da saúde pública a partir da criação de novas legislações e espaços de cuidado. É seguindo o viés da saúde pública e da inclusão da questão do uso problemático de drogas no âmbito de intervenção das políticas públicas que são pensadas e postas em prática novas formas de cuidado a esses indivíduos, a exemplo dos Centros de Atenção Psicossocial para usuários de Álcool e outras Drogas (CAPS AD)9.

O CAPS AD, de acordo com as premissas da reforma psiquiátrica, é um serviço público, de atenção diária, voltado não só para o tratamento dos usuários em relação ao uso de drogas mas, também, para sua reinserção familiar, social e comunitária. O CAPS propõe a quebra do modelo de cuidado tradicional, alterando a maneira de lidar com o sofrimento mental e seus determinantes. O cuidado aos usuários passa a ser prestado nesses serviços de lógica comunitária, visando a atuação no próprio território de cobertura e ampliando o processo de cuidado aos familiares e a questões de âmbito social ${ }^{9-13}$.

Diante da importância desse serviço no cuidado aos indivíduos que fazem uso problemático de drogas - uma vez que o mesmo representa um avanço em relação ao modelo asilar e excludente anterior à reforma psiquiátrica -, cabe perguntarmos: Quais são o significado e o sentido que o serviço tem para os usuários? O que eles procuram? Como entendem e vivenciam o serviço?

Significado e sentido são compreendidos e abordados, nesse trabalho, como categorias diferentes, porém constituintes. O significado diz respeito ao constructo social, ao que é vivenciado em grupo, na coletividade. O sentido, por sua vez, abarca a individualidade, ou seja, aquilo que é apreendido pelo indivíduo a respeito de algo, mas que não o descola do meio social ${ }^{14}$. A respeito dos termos significado e sentido, retratam Paula et al. ${ }^{15}$ :

[...] significado corresponde a um sistema de relações que foi constituído de forma objetiva através de um processo histórico, ou seja, quando o significado da palavra é assimilado, apreende-se a experiência social. Já o sentido corresponde ao individual e pode designar algo completamente diferente de pessoa para pessoa e em circunstâncias diversas. (p. 123) 
Embora ambas as categorias tenham relação com o meio social, podendo representar conteúdos diversos com o transcorrer dos acontecimentos que envolvem a existência, o significado relaciona-se a conteúdos mais consolidados. Já o sentido representa uma região mais oscilante, uma vez que tem um perfil mais abrangente ${ }^{16}$. Em outras palavras, o significado concerne às representações coletivas a respeito de um determinado assunto. Representações essas que, ao serem apropriadas pelos indivíduos, sofrem configurações referentes às subjetividades de cada um. Por outro lado, o sentido remete ao indivíduo e às suas particularidades, mas sem deixar de levar em conta a ligação com o contexto social. Sobre o sentido, referem Aguiar e Ozella ${ }^{16}$ :

[...] o sentido subverte o significado, pois ele não se submete a uma lógica racional externa. $\mathrm{O}$ sentido refere-se a necessidades que, muitas vezes, ainda não se realizaram, mas que mobilizam o sujeito, constituem o seu ser, geram formas de colocá-lo na atividade. O sentido deve ser entendido, pois, como um ato do homem mediado socialmente. A categoria sentido destaca a singularidade historicamente construída. (p. 227)

Tendo em vista os conceitos supramencionados e o papel das drogas na vida em sociedade, esse estudo teve como objetivo identificar os significados e sentidos do CAPS AD para seus usuários, levando em conta esses sujeitos em sua totalidade e seus objetivos com o tratamento.

\section{Metodologia}

O presente estudo foi realizado em um CAPS AD II, localizado na região Sudoeste da cidade de Campinas, e teve como abordagem a pesquisa qualitativa. Para coletar os dados, foram realizadas nove visitas ao serviço, resultando em sete meses de pesquisa de campo e 11 entrevistas efetuadas. O instrumento de coleta de dados utilizado foi a entrevista semiestruturada, e os depoimentos foram analisados a partir do método de análise de conteúdo. Segundo Bardin ${ }^{17}$, a análise de conteúdo é "[...] um conjunto de técnicas de análise das comunicações que utiliza procedimentos sistemáticos e objetivos de descrição do conteúdo das mensagens" (p. 40).

É importante reforçar que o método qualitativo não se resume à não adesão de números, porcentagens, cálculos, etc. ${ }^{18}$, mas que, para além disso, procura identificar significados, opiniões e representações descritas a partir de diálogos. Nesse sentido, o método qualitativo nos pareceu ser ideal para esse estudo. A respeito desse tipo de metodologia, Turato ${ }^{18}$ discorre:

No contexto da metodologia qualitativa aplicada à saúde, emprega-se a concepção trazida das Ciências Humanas, segundo as quais não se busca estudar o fenômeno em si, mas entender seu significado individual ou coletivo para a vida das pessoas. Torna-se indispensável assim saber o que os fenômenos da doença e da vida em geral representam para elas. O significado tem função estruturante: em torno do que as coisas significam, as pessoas organizarão de certo modo suas vidas, incluindo seus próprios cuidados com a saúde. (p. 509)

A escolha da entrevista individual semiestruturada como instrumento de coleta de dados se justifica devido à complexidade e à especificidade do campo e dos entrevistados. Desta forma, buscou-se não limitar as questões a serem abordadas, levando em conta informações que não estavam previstas, mas sem perder o foco da pesquisa.

No começo de cada entrevista, solicitamos que o usuário entrevistado dissertasse sobre a sua história de vida, sempre relacionando com o uso de drogas até o momento atual e sua relação com o CAPS. Cada entrevista teve duração de vinte a 49 minutos, e só pôde ser realizada mediante leitura e assinatura do Termo de Consentimento Livre e Esclarecido (TCLE). Todas as entrevistas foram gravadas com autorização dos participantes, resultando num total de cinco horas, 36 minutos e 46 segundos de áudio gravado, que, posteriormente, foram transcritos para a realização da análise. 
Focando na viabilidade da execução da pesquisa no que tange ao acesso aos usuários, a amostra se deu de forma intencional e por conveniência, uma vez que, ao mesmo tempo em que houve critérios para a seleção dos entrevistados, o exame qualitativo foi proposto apenas para aqueles que estavam presentes no serviço no dia em que as entrevistas foram realizadas, ou seja, sem agendamento prévio.

Por ser uma pesquisa qualitativa, a amostra foi selecionada tendo em vista sua diversidade e abrangência para o procedimento de assimilação ${ }^{19}$. Desta forma, os critérios de inclusão para participar da entrevista foram: usuários que já tinham, pelo menos, um mês de acompanhamento no CAPS; homens e mulheres; diferentes drogas de uso, e que foram acolhidos no serviço entre os anos de 2012 e 2015.

A quantidade de usuários entrevistados foi determinada pelo critério de saturação, que, segundo Minayo ${ }^{19}$, representa "o conhecimento formado pelo pesquisador, no campo, de que conseguiu compreender a lógica interna do grupo ou da coletividade em estudo" (p. 197-8).

Na medida em que as entrevistas foram realizadas, os passos dados em seguida foram as transcrições e, por fim, as análises. Nesse caminhar, identificamos colocações bastante variadas, mas que, com o decorrer do processo de investigação, foram se aproximando e desvelando similaridade entre os entrevistados. Ao verificarmos que os objetivos estavam contemplados nos relatos desses indivíduos, com distinções e familiaridades, finalizamos o processo de coleta de dados.

Durante o processo de avaliação das entrevistas, o caminho foi percorrido da seguinte maneira, de acordo com Bardin ${ }^{17}$ : descrição analítica - "enumeração das características do texto, resumida após tratamento"; inferência - dedução lógica - interpretação - "significação concedida a estas características" (p. 41).

$\mathrm{Na}$ análise de conteúdo, foram identificadas as categorias mais presentes nos discursos dos entrevistados, assim como ideias semelhantes, expressões e palavras recorrentes. Tendo em vista a importância das singularidades das falas e histórias contadas, foi feita uma "decifração estrutural" de cada entrevista ${ }^{17}$. A decifração foi realizada com auxílio da análise de enunciação, análise essa que, segundo Minayo ${ }^{19}$ :

Considera que na produção da palavra elabora-se, ao mesmo tempo, um sentido e operam-se transformações. O discurso não seria um produto acabado, mas um momento de criação de significados com tudo o que isso comporta de contradições, incoerências e imperfeições. Esse tipo de estudo parte da ideia de que, nas entrevistas, a produção da fala é, ao mesmo tempo, espontânea e constrangida pela situação. (p. 312)

Todas as entrevistas foram iniciadas com uma pergunta disparadora que convidou os entrevistados a dissertarem livremente sobre: suas trajetórias de vida em relação ao uso, sua chegada no CAPS, e o que isso trouxe de consequências para a sua vida. A essa pergunta, cada usuário respondeu de uma forma diferente.

Dentre tantas informações que puderam ser constatadas, foi possível identificar, na fala dos entrevistados, 59 categorias, das quais 43 se repetiram, pelo menos, uma vez entre eles. Dentre as categorias mais presentes nos discursos, estão: a história de uso da droga, a relação familiar, relatos de infância, visão do CAPS, e consequências do tratamento e rotina de uso. Não cabendo a esse artigo abordar todas as 59 categorias, daremos especial destaque ao que foi proposto como objetivo dessa pesquisa.

No que tange às questões éticas desse estudo, participaram das entrevistas somente os pacientes que aceitaram dar sua contribuição, tendo a liberdade de desistir da sua participação a qualquer momento. A identidade dos entrevistados foi mantida em anonimato, levando em conta a Resolução 466/12, a qual regulamenta as pesquisas em seres humanos no Brasil e atualiza a Resolução 196/96. O projeto foi submetido e aprovado pelo Comitê de Ética em Pesquisa. 


\section{Análise e discussão: significados e sentidos do CAPS AD}

Decifrar os significados e sentidos que o CAPS tem para seus usuários indica compreender: suas formas de se relacionarem com o serviço, quais demandas buscam responder com esse cuidado especializado, e como o CAPS responde às suas demandas e solicitações. Dito isto, foi possível identificar quatro categorias apresentadas nas falas dos usuários em relação ao sentido e significado do CAPS: local de acolhimento, apoio e cuidado; espaço de resolução de problemas dos usuários; local que reinsere socialmente; e, por último, um serviço ineficiente em suas ações.

O significado atribuído ao CAPS como um serviço de acolhimento, apoio e cuidado foi relatado de maneira quase que unânime entre os usuários. Dentro dessa categoria, surgiram falas que descreviam o CAPS como um local onde é possível encontrar forças para continuar e contar com o auxílio de pessoas que estão sempre dispostas a ouvir e contribuir com suas colocações. Essa identificação do CAPS como um espaço de acolhimento pode ser vista, também, em outras pesquisas ${ }^{20,21}$.

Para a maioria, o CAPS foi significado como um local que proporciona coisas boas e que sempre recebe seus usuários de portas abertas. Algumas colocações elucidando esse significado do CAPS como espaço amigável chamaram particular atenção:

"[...] vim e pedi ajuda de novo aqui, porque aqui é o único lugar que pode me ajudar [...]". (Mulher, 37 anos)

"As pessoas tratam a gente aqui muito bem [...]". (Homem, 57 anos)

“Eu acho um lugar seguro. Um lugar bom, um lugar que protege, um lugar que dá assistência que a gente precisa. Pra falar a verdade, se tivesse alguma coisa de ruim eu falaria, porque não tenho porque esconder nada de ninguém, porque eu não devo nada pra ninguém daqui, então ninguém me deve nada pra mim. A única coisa que eu devo é satisfação, entendeu? $\mathrm{E}$ agradecimento de tudo que eles já fizeram por mim [...]". (Mulher, 37 anos)

"Assim, eu mesmo, é igual eu tava falando pro pessoal que veio aqui. Antigamente eu falava assim 'ah é, eles estão lá só porque eles estão sendo pagos, porque senão eles não tavam nem aí'. Algumas pessoas pode ser que seja assim, só que, eu fui tratada de uma forma assim, eles me acolheram aqui de uma forma assim tão carinhosa que eu me apeguei aos funcionários aqui do CAPS, entendeu?! Então assim, é igual eu falo pra eles, que eu agradeço muito todo o apoio que eles tava me dando, porque foi o que me ajudou, entendeu?! [...]". (Mulher, 20 anos)

"Agora aqui, quando eu corro pra cá, eu já me sinto bem porque o pessoal daqui trata a gente bem [...]". (Homem, 53 anos)

"Aqui eu me sinto bem e sou bem acolhido, apoiado. Falando por mim. Cada um tem um jeito de pensar né. Mas eu sou bem recebido, eu creio que sim. Acho que [...] eu gosto de tudo, de todas as pessoas, os profissionais. Eu acho também que todo mundo gosta de mim, num sei né, eu creio que sim [...]". (Homem, 44 anos)

Na mesma intensidade em que os usuários reconhecem o serviço de maneira positiva, eles deslegitimam a própria capacidade de crítica ao espaço. Quando solicitados a opinar sobre o serviço, quase sempre começavam suas argumentações diminuindo a si mesmos, como se, em decorrência da situação de dependência de drogas, não fossem capazes de fazer críticas a esse espaço. 
“Crítica eu não tenho, crítica eu não tenho, nenhuma não, eu só tenho que agradecer a eles aí por essa força que eles nos dá né [...]". (Homem, 60 anos)

“Olha, eu vou ser sincero. Eu não tenho crítica nenhuma pra fazer, entendeu?! Acho que todo mundo desenvolve o seu papel aqui perfeitamente, você entendeu?! É [...] honestamente dizendo, eu num tenho que criticar, num tenho [...]". (Homem, 41 anos)

"Ah, não. Eu? Quem sou eu pra criticar? Não posso criticar ninguém, nem cada um né". (Homem, 44 anos)

Por outro lado, fora as consequências positivas do CAPS na vida desses usuários e o vínculo de respeito e confiança que é desenvolvido e conservado, há, também, um movimento de transição entre a relação de cuidado e troca para o de dependência do espaço na resolução de diversas questões do cotidiano.

Ao mostrá-lo como um local acolhedor e que proporciona o acesso a direitos para além da saúde, em algumas falas, foi perceptível uma relação de dependência muito intensa entre alguns usuários e o CAPS, em que os primeiros acabavam transferindo ao serviço a função de resolver demandas que não dizem respeito às atribuições dessa instituição. Esse contexto chama a atenção para o sentido conferido a essa instituição como um espaço de resolução de problemas dos usuários, deixando o tratamento em segundo plano.

É sabido que o público que, em geral, frequenta o CAPS é pertencente a camadas mais pobres ${ }^{22}$, e, diante desse contexto, sofre de carências consequentes da desarticulação e omissão de políticas públicas. Desta forma, ao enxergarem no CAPS a possibilidade de acesso a direitos sociais antes negligenciados, acabam, muitas vezes, realizando um movimento de cronificação na rede ${ }^{23,24}$.

Ao ser indagada se, a partir do CAPS, ela vem tendo acesso a mais direitos, uma usuária respondeu: "Mais acesso, eu tenho mais ajuda. Sozinha eu não tenho ajuda de ninguém" (Mulher, 37 anos).

Por outro lado, quando questionada a respeito do sentimento de autonomia a partir dos direitos acessados, ela trouxe: "Ah, por enquanto sim, né, mas não totalmente. Eu queria ter ganhado a minha casa, ninguém resolve nada pra mim [...]" (Mulher, 37 anos).

O diálogo apresentado indica o sentido do CAPS para essa usuária e coloca, em xeque, uma possível debilidade do serviço na promoção da autonomia, que se constitui como uma das diretrizes para o funcionamento da Rede de Atenção Psicossocial (RAPs) ${ }^{25}$. Ao mesmo tempo que a usuária reconhece um maior acesso a direitos, ela transfere, ao CAPS, uma função que não está a cargo do serviço e se desresponsabiliza da ação.

O sentido do CAPS como ambiente de reinserção social também se fez manifesto. Ocorreram relatos em que houve um reconhecimento das ações e articulações desse serviço para a reinserção de seus usuários na sociedade. Essa interpretação esteve presente em usuários em acompanhamento no serviço há mais de dois anos, que se referem à boa relação com os funcionários e à forte relação de vínculo.

"Às vezes você tá meio perdidão, tipo, você para de usar droga, mas não sabe como você vai voltar ao convívio social, entendeu?! E o CAPS ajuda em tudo isso. Porque o CAPS ele ajuda, porque de uma forma ele não faz assim, oh: eu vou tratar você, você vai parar de usar droga, parou de usar droga e tchau. Não, ele prepara tudo. Ele traz a gente, a gente faz o tratamento. Na hora que a gente tiver bem eles ajudam a voltar ao convívio na sociedade, entendeu!? [...]". (Mulher, 20 anos)

Para além dos sentidos fundamentados no reconhecimento de apoio, cuidado e reinserção social, relatos relacionados ao desprezo também foram assinalados, como mostra a fala: "Aqui eles estão me desprezando. Num tem outra consulta marcada pra mim. Eu vim pra cá num sei como. Eu venho pra ser consultado e eles não aceita. Num fala nada" (Homem, 37 anos).

Quando questionado sobre sua opinião a respeito do tratamento, esse mesmo usuário respondeu: "Tem vez que é muito demorado pra atender a gente. Num tenho muita paciência, ficar sentado 
esperando. Demora muito [...] Eu num sei se é porque é muito serviço pra eles. Eles marcam um horário, num é esse" (Homem, 37 anos).

O sentido do CAPS como um local que despreza, tendo como base as críticas do usuário supramencionado, pode ser reflexo de um serviço que atende a uma demanda maior do que sua própria capacidade. Diante disto, chamamos atenção para algumas informações importantes a respeito do serviço. Embora a instituição em estudo seja um CAPS II e esteja localizada na região Sudoeste da cidade, ela é responsável por atender tanto sua região de instalação quanto a região Noroeste. De acordo com dados da Prefeitura de Campinas de 2010, a região Sudoeste da cidade abrangeu 234.804 habitantes, e a Noroeste, 123.484. Juntando as duas regiões, há um total de 358.288 habitantes, sendo que esse quantitativo de indivíduos reside na área de cobertura desse CAPS AD ${ }^{26}$.

Logo, por ser um CAPS II, de atenção diária, e contar com uma equipe reduzida, esse serviço precisa se desdobrar para dar conta das demandas diárias. Com isso, certamente, nem todas as necessidades dos usuários poderão ser atendidas, gerando críticas ao processo de trabalho. Esse quadro chama atenção para a emergência de novas estratégias de organização, de forma que não sobrecarregue a equipe e não desassista seus usuários.

\section{Considerações finais}

Consumir drogas é um fenômeno antigo que, provavelmente, existe desde o surgimento da humanidade. Esse ato está relacionado a outras manifestações humanas como: a cultura, a busca por sensações prazerosas e, também, a manutenção da vida. Embora o uso de drogas seja algo muito presente em nosso cotidiano e faça parte de cerimônias religiosas e manifestações culturais, pode proporcionar sensações e consequências não esperadas e/ou desejadas a priori, se mal administrado. É no enredo do uso de drogas que extrapola as dinâmicas sociais e que pode ocasionar - ou ser fruto de - problemas familiares, sociais, psicológicos e de saúde, que este trabalho se debruçou.

Esse trabalho mostrou que, para a maioria dos usuários, o CAPS é significado como um local de apoio, ajuda e acolhimento. Local que mantém as portas abertas para recebê-los sempre que necessitam e quantas vezes for preciso. Ao respeitar as escolhas dos usuários e atender às demandas para além do mero uso de drogas, o CAPS estabelece vínculos importantes com esses indivíduos.

Tendo em vista que o CAPS é uma instituição pensada para lidar com a questão do uso abusivo e/ou dependente de drogas tanto no âmbito psicológico quanto no social, ele oferta serviços que buscam atender a tais demandas de maneira integrada. Com vistas ao acesso à saúde, cidadania e reinserção social, o CAPS possibilita o uso de transporte gratuito e auxilia na retirada de documentos sem que haja custos, e lança mão de atividades do tipo laborativa com retorno financeiro.

Defendem-se como fundamentais todas as ações supracitadas, e há o reconhecimento de sua indispensabilidade no processo terapêutico. No entanto, em detrimento da vulnerabilidade social de alguns dos usuários, ao verificar a possibilidade de acesso a direitos e benefícios através do CAPS, o tratamento, às vezes, perde sua função terapêutica, e passa a ter como objetivo principal a resolução de questões sociais.

Nessa lógica, a promoção de autonomia deixa a desejar e, em seu lugar, é preservada uma relação de dependência com o serviço. Esse movimento remete a uma possível desarticulação entre as políticas públicas de saúde e assistência social, o que pode ser fruto de uma lacuna nas práticas de intersetorialidade. Preserva-se a argumentação de que esse quadro não pode ser visto de forma isolada, apenas a partir do CAPS, sendo necessário estudar, em conjunto, as práticas de ações em outras instituições da rede de atenção psicossocial.

Os comentários de um dos usuários a respeito do desprezo que sente dentro do CAPS e da demora para ser atendido podem ser reflexo de um serviço sobrecarregado. Esse quadro chama atenção para a necessidade de fundação de outros CAPS ou de ampliação do mesmo serviço para que possa atender às demandas de forma eficiente.

No geral, o significado que o CAPS tem para esses indivíduos é de um espaço que acolhe e cuida. Cuidado este que, ao ser exercido, vem criando relações de vínculo e, assim, potencializando a 
terapêutica do espaço. Por outro lado, também carrega outros sentidos, uma vez que, ao representar acesso aos direitos e benefícios antes inalcançáveis, gera dependência, podendo caminhar na

contramão da produção de autonomia. É preciso ponderar entre o acesso a direitos e à construção de autonomia, de forma que o serviço não deixe de atuar no âmbito social desses usuários e possa, de forma conjunta, promover a reinserção social e o empoderamento desses indivíduos.

\section{Colaboradores}

As autoras participaram ativamente na discussão dos resultados, revisão e aprovação da versão final do trabalho.

\section{Referências}

1. Simões JA. Prefácio. In: Carneiro HS, organizador. Drogas e cultura: novas perspectivas. Salvador: Edufba; 2008. p. 13-21.

2. Helman CG. Cultura, saúde e doença. 5a ed. Porto Alegre: Artmed; 2009.

3. Tófoli LF. Conceitos básicos nos transtornos de uso, abuso e dependência de crack, álcool e outras drogas. In: Mazitelli F, Santos V, Malcher MN, Santos J, Nogueira D, Obara $M$, et al., organizadores. Desenvolvendo e articulando o conhecimento para o cuidado das pessoas em sofrimento pelo uso de drogas em contextos de vulnerabilidade. Curitiba: CRV; 2015. p. 35-43.

4. Uchôa R. Jovens, lazer e consumo de drogas. Recife: Arte Sensu; 2007.

5. Labate BC, Fiore M, Goulart SL. Introdução. In: Carneiro HS, organizador. Drogas e cultura: novas perspectivas. Salvador: Edufba; 2008. p. 23-38.

6. Carneiro HS. A fabricação do vício [Internet]. In: Anais do $13^{\circ}$ Encontro Regional de História; 2002; Belo Horizonte, Brasil. Belo Horizonte: Revista de História - Departamento de História/ICHS/UFOP; 2002. [citado 15 Jun 2015]. Disponível em: http://www.neip. info/downloads/t_hen1.pdf

7. Fiore M. Uso de "drogas": controvérsias médicas e debate público. Campinas: Mercado de Letras; 2007.

8. Carneiro HS. As necessidades humanas e o proibicionismo das drogas no século XX. Rev Outubro. 2002; 6(6):115-28. 
9. Ministério da Saúde (BR). Portaria/GM n 336, de 19 de fevereiro de 2002. Define as normas e diretrizes para a organização dos serviços que prestam assistência em saúde mental. Brasília (DF): Ministério da Saúde; 2002.

10. Ministério da Saúde (BR). A política do Ministério da Saúde para a atenção integral a usuários de álcool e outras drogas. Brasília (DF): MS; 2003.

11. Luzio CA, L'abbate S. A reforma psiquiátrica: aspectos históricos e técnicosassistenciais das experiências de São Paulo, Santos e Campinas. Interface (Botucatu). 2006; 10(20):281-98.

12. Brasil. Reforma Psiquiátrica e política de Saúde Mental no Brasil. In: Conferência Regional de Reforma dos Serviços de Saúde Mental: 15 anos depois de Caracas; 2005; Brasília. Brasília: OPAS; 2005. p. 5-51.

13. Surjos LTLS, Onocko-Campos R. A avaliação dos usuários sobre os Centros de Atenção Psicossocial (CAPS) de Campinas, SP. Rev Latino-Am Psicopatol Fund. 2011; 14(1):122-33.

14. Wazlawick P, Camargo D, Maheirie K. Significados e sentidos da música: uma breve "composição" a partir da psicologia histórico-cultural. Psicol Estud. 2007; 12(1):105-13.

15. Paula ML, Jorge MSB, Albuquerque RA, Queiroz LM. Usuário de crack em situações de tratamento: experiências, significados e sentidos. Saude Soc. 2014; 23(1):118-30.

16. Aguiar WMJ, Ozella S. Núcleos de significação como instrumento para a apreensão da constituição de sentidos. Psicol Cienc Prof. 2006; 26(2):222-45.

17. Bardin L. Análise de conteúdo. Lisboa: Edições 70; 2010.

18. Turato ER. Métodos qualitativos e quantitativos na área da saúde: definições, diferenças e seus objetos de pesquisa. Rev Saude Publica. 2005; 39(3):507-14.

19. Minayo MCS. O desafio do conhecimento: pesquisa qualitativa em saúde. 14a ed. São Paulo: Hucitec; 2014.

20. Oliveira RF, Andrade LOM, Goya N. Acesso e integralidade: a compreensão dos usuários de uma rede de saúde mental. Cienc Saude Colet. 2012; 17(11):3069-78.

21. Cardona HEH. Gerenciamento de caso em usuários de crack: contribuições para o tratamento e qualificação da intervenção profissional de um CAPS ad do DF [dissertação]. Brasília (DF): Universidade de Brasília; 2013.

22. Rosa LCS, Onocko-Campos RT. Saúde mental e classe social: CAPS, um serviço de classe e interclasses. Serv Soc Soc. 2013; (114):311-31.

23. Surjus LTLS. Narrativas políticas: o olhar dos usuários sobre os CAPS (Centros de atenção psicossocial) de Campinas [dissertação]. Campinas (SP): Universidade Estadual de Campinas; 2007.

24. Costa PHA. Mapeamento da rede de atenção aos usuários de drogas: um estudo exploratório [dissertação]. Juiz de Fora (MG): Universidade Federal de Juiz de Fora; 2014.

25. Ministério da Saúde (BR). Portaria no 3.088, de 23 de Dezembro de 2011. Institui a Rede de Atenção Psicossocial para pessoas com sofrimento ou transtorno mental e com necessidades decorrentes do uso de crack, álcool e outras drogas, no âmbito do Sistema Único de Saúde (SUS). Brasília (DF): Ministério da Ssaúde; 2011.

26. Campinas. Município de Campinas [Internet] [acesso 2015 Jun 30]. Disponível em: http://www.campinas.sp.gov.br/governo/seplama/publicacoes/populacao_residente_ grandes_regioes.php 
Lacerda CB, Fuentes-Rojas M. Significados y sentidos atribuidos al Centro de Atención Sicosocial Alcohol y otras Drogas (CAPS AD) por sus usuarios: un estudio de caso. Interface (Botucatu). 2017; 21(61):363-72.

El objetivo de este artículo es presentar los significados y sentidos que un Centro de Atención Sicosocial Alcohol y otras Drogas (CAPS AD) tiene para sus usuarios. En este estudio de carácter cualitativo se realizaron entrevistas semi-estructuradas con once usuarios que eran acompañados en el servicio. Los significados y sentidos más presentes en los discursos indicaron una relación positiva con el servicio, visto como un local de apoyo y cuidado. También se constató que el CAPS, al mostrarse como local acogedor y que proporciona el acceso a derechos que van más allá de la salud, precisa ponderar entre el acceso a derechos y beneficios y la construcción de autonomía para que el servicio no deje de actuar en el ámbito social, sino que también pueda promover la reinserción social y el empoderamiento de esas personas.

Palabras clave: CAPS AD. Significados y sentidos. Drogas. 